\title{
Discharge report for the community pharmacist: Development and validation of a prototype
}

\author{
Joke Wuyts $^{\mathrm{a}, *}$, Marie Vande Ginste ${ }^{\mathrm{a}}$, Jan De Lepeleire ${ }^{\mathrm{b}}$, Veerle Foulon ${ }^{\mathrm{a}}$ \\ ${ }^{a}$ KU Leuven, Department of Pharmaceutical and Pharmacological Sciences, 3000, Leuven, Belgium \\ ${ }^{\mathrm{b}} \mathrm{KU}$ Leuven, Department Public Health and Primary Care, 3000, Leuven, Belgium
}

\section{A R T I C L E I N F O}

\section{Keywords:}

Patient discharge [mesh]

Continuity of care

Community pharmacy

Patient safety

Health information exchange

Belgium

\begin{abstract}
A B S T R A C T
Background: The potential benefit of community pharmacist's involvement in continuity of care is well-known. However, it is not standard practice to exchange information with the community pharmacist (CP) after hospitalization.

Objective: To construct and validate an evidence-based prototype of a discharge report for the community pharmacist.

Methods: First, a review of literature, guidelines and established initiatives was performed to construct a preliminary discharge report. Secondly, the content of the discharge report was reviewed and optimized using semistructured individual interviews with CPs and general practitioners (GPs).

Results: The review identified six guidelines for information exchange with the $\mathrm{CP}$ originating from three countries, 17 research papers and three local initiatives. Overall, 49 different elements for a discharge document were identified. Based on recurring elements, a preliminary discharge report was created. Interviews with ten CPs and nine GPs provided insights into which information is considered crucial for patient safety and why. This allowed an optimization of the document. The final discharge report consists of three categories: administrative, medication and medical data. The medication data includes medication registered at hospital admission as well as at hospital discharge, drug indications, reasons for initiating, adjusting or discontinuing therapies and start/ stop dates. The medical data contains reasons for hospitalization, comorbidities and allergies.

Conclusions: The literature review and semi-structured interviews resulted in an evidence-based prototype of a discharge report for the community pharmacist. This document contains both administrative, medical and medication data.
\end{abstract}

\section{Introduction}

Continuity of care or seamless care describes 'efficient, effective, ethical care delivered through interaction, integration, coordination and sharing of information between different healthcare actors over time'. ${ }^{1}$ Multiple researchers have demonstrated that patients experience discontinuity at hospital discharge. ${ }^{2}$ Moreover, patient safety may be endangered as hospital discharge entails a risk for drug-related problems, ${ }^{2}$ adverse events ${ }^{3}$ and even readmissions. ${ }^{4,5}$ In 2010, a research report was published by the Belgian Healthcare Knowledge Centre concerning the continuity of medication therapy between the hospital and ambulatory care. ${ }^{6}$ Focus groups with multiple healthcare professionals (HCPs) identified problems related to admission and discharge, problems related to the profession, to patients and family and problems related to the process. ${ }^{6}$ Most problems originated from a lack of information for the healthcare professionals and a lack of communication between HCPs. Similarly, Karapinar et al. postulates three causes for medication errors at transitions of care: insufficient patient information, insufficient communication between healthcare providers and incomplete medication lists with subsequently inappropriate medication reconciliation. ${ }^{7}$

This paper will focus on information exchange between hospital physicians and community pharmacists as a method to improve patient safety during the transfer from the hospital to primary care. Accurate, up-to-date information allows HCPs to perform medication reconciliation and subsequently counsel the patient after hospital discharge. Information transfer to general practitioners (GPs) at discharge has been studied extensively and is standard practice in Belgium. ${ }^{8-10}$ In

${ }^{*}$ Corresponding author. Clinical Pharmacology and Pharmacotherapy, Department of Pharmaceutical and Pharmacological Sciences, Herestraat 49 O\&N2 box 521, 3000, Leuven, Belgium.

E-mail addresses: joke.wuyts@kuleuven.be (J. Wuyts), marie_vande_ginste@hotmail.com (M. Vande Ginste), jan.delepeleire@kuleuven.be (J. De Lepeleire), veerle.foulon@kuleuven.be (V. Foulon). 
addition to the role of the GP, research has shown that the community pharmacist (CP) also contributes to continuity of care after a hospitalization. ${ }^{11}$

In recent years, the role of the community pharmacist in Belgium has evolved towards clinical, non-dispensing services. Currently, three pharmaceutical care service are remunerated in Belgium and can be provided by every community pharmacist. Two of those services focus on adequate use of medication for specific pathologies (asthma and diabetes respectively). ${ }^{12,13}$ In 2017 , the service 'reference pharmacist' was introduced. ${ }^{14}$ This service is remunerated for ambulatory patients with chronic diseases. In brief, a reference pharmacist (1) registers all the patient's dispensed medication in the patient's pharmaceutical dossier, (2) constructs and updates a medication list for his/her patients and (3) ensures the patients (and their care team) have access to an upto-date medication list. Future perspectives include an intermediate medication review service. To date, Belgian pharmacists do not have access to clinical data such as medication indications, lab values or renal function. No specific pharmacist-led service exists for discharged patients (e.g. a medication reconciliation service with discharge counselling).

As an example of healthcare digitalization in Belgium, electronic prescribing is currently being implemented. Moreover, the Flemish government (Flanders is a region in Belgium with approximately 6.500.000 inhabitants) has developed a secured, electronic platform 'Vitalink' to organize health information exchange between HCPs. ${ }^{15}$ Upon patients' consent, physicians and pharmacists can add, adapt and delete a medication list of the patient on this platform. To date, the implementation of Vitalink is limited and information exchange between HCPs is not yet standard practice. This is because not all GPs and CPs can access the platform with their software and the platform is not yet operational in hospitals. ${ }^{15}$ From a content perspective, only the current medication list can be exchanged with Vitalink. The application does not offer the possibility to annotate changes or look back at previous medication lists. It is questionable whether this information, as exchanged in Vitalink, will be sufficient to perform medication reconciliation and patient counselling after hospital discharge.

Information exchange upon hospital discharge in Belgium consists of (1) a letter for the GP (2) medication prescriptions and (3) in some cases a medication list is provided for the patient. Because communication to the $\mathrm{CP}$ is limited to indirect communication through prescriptions, there is a risk that the pharmacist does not have a complete overview of the patients' situation.

Little research focused on the content of the information that should be exchanged at discharge with the community pharmacist. Therefore, this research aims to develop an evidence-based prototype of a discharge report for the $\mathrm{CP}$, as a basic medication list may not be sufficient. Unlike a medication report which is limited to medication information, a discharge report is defined as a 'clinical report concerning a completed mandated period of care'. ${ }^{1}$ It should contain all relevant information for the community pharmacist.

\section{Aim of the study}

To construct and validate a prototype for a discharge report for the community pharmacist. This discharge report should be tailored to the pharmacists' informational needs post-discharge, and to the pharmacists' role in ensuring patient safety by dispensing medication in a responsible way and providing patient counselling after hospital discharge.

\section{Method}

\subsection{Literature review and construction of a preliminary discharge report}

First, a literature review was performed to identify initiatives in which information is shared with the community pharmacist at hospital discharge and to summarize the content of the discharge information. For this purpose, both peer-reviewed publications in the database "Medline" as well as grey literature published before November $30^{\text {th }}$, 2016 were included. The search strategy for Medline combined the concepts community pharmacy, hospital discharge, discharge document, their synonyms and related Medical Subject Headings (MeSH) terms (displayed in Supplementary material 1). Strategies for the collection of grey literature were (1) references to national or regional guidelines in published studies (2) personal knowledge, by members of the research team, of on-going local clinical pharmacy initiatives.

The following two inclusion criteria were applied:

- Information exchange that comprised more than a basic list of the medication at discharge. A basic list contains the name, quantity and time of intake of the medication and a remark section.

- Exchange with, but not necessarily limited to, the CP

No restrictions on type of research, language or publication date were imposed. Aside from research articles, also websites and documents were eligible sources of information.

One researcher (JW) performed data selection. The findings were organized and summarized per initiative, as multiple sources of info could refer to one single initiative. The content of each discharge document was categorized into administrative, medical and medication data. These categories were developed inductively based on the identified content. Next, recurring elements were identified. The research team (JW, MVDG, VF and JDL, researchers with a CP and GP background) discussed the findings of the literature search and constructed a preliminary discharge report.

\subsection{Validation of the discharge report}

\subsubsection{Design}

In a second step, the content of the preliminary discharge report was reviewed by CPs and GPs. Face-to-face, semi-structured individual interviews were performed using an interview guide and covered a range of topics related to medication counselling after hospital discharge. Topics included hurdles and facilitators in current practice, as well as actions to optimize continuity of pharmacotherapy upon hospital discharge that were considered supportive and feasible, including a proposal for a discharge report. A thematic framework approach was used for the analysis of all topics in the semi-structured interviews. ${ }^{16}$ This paper reports on the results pertaining to the proposed discharge report; other findings are embedded in a separate manuscript. ${ }^{17}$

\subsubsection{Content}

The preliminary discharge report for a clinical case was shown in the interviews using a PowerPoint presentation. The report contained administrative data, medical data and medication data. Medication data included a medication list upon admission and discharge, reasons for drug adjustments, initiation or cessation, drug indication and active compound per drug. In each interview, it was emphasized that the document was specifically intended for the CP. Upon presenting the preliminary discharge report to the participants, they were asked what information they considered (not) relevant to exchange and why. Participants were asked to give examples on how this information could improve patient care and safety. To ensure all relevant components were included in the discharge report, the interviewer asked if any additional information should be added to the discharge report.

\subsubsection{Participants}

At the start of the study, a purposive sampling strategy to invite opinion leaders was chosen. The researchers perceived opinion leaders to be the most informative to explore optimization methods for medication counselling after hospital discharge and to critically review the content of a discharge report. Opinion leaders were defined as GPs and 
CPs with experience in daily practice and who also have an interest in research or optimization of healthcare. Participants were recruited via healthcare professional associations. The sampling strategy was modified throughout the study upon discussions within the research team. Due to the low response rate, the sample was expanded to non-opinion leaders, HCPs who have experience with daily practice but do not necessarily have experience with research. After conducting the study, the researchers believe that the inclusion of non-opinion leaders has further enriched the findings, as this led to maximal variation of the participants in the study. Individual interviews were carried out in two regions in Flanders to obtain a diverse population with experience with multiple hospitals. CPs and GPs were interviewed alternatingly. Through an iterative process, findings from previous interviews were incorporated in future interviews.

\subsubsection{Data collection and analysis}

Interviews took place between October 2015 and April 2016 and were conducted by two researchers who had no relationship with the interviewed HCPs (JW, MVDG, both with a pharmacy background). The two researchers (JW and MVDG) developed the research protocol and topic guide together. The first interview with a GP and CP served as a pilot interview. Each interviewer performed one of the pilot interviews; both attended. This allowed the researchers to ensure the quality of the interviews and ensure the same attitude and goals were set. Both pilot interviews were included in the study results.

Interviews were performed until there was saturation of information and no new arguments on the relevance of the elements in the discharge report emerged. ${ }^{18}$ The saturation was determined by the researchers for GPs and CPs separately. Additional descriptive information of the interviewees was collected (gender, years of experience, experience as opinion leader, type of practice, type of patients and number of colleagues in their own practice). All interviews were audiotaped, the identity of the participants was encoded during transcription and the recordings were destroyed.

A thematic framework approach was used for the data analysis. First, each interview was transcribed verbatim by the researcher who performed the interview. After familiarization with the interviews, one researcher (MVDG) designed a coding scheme to categorize the collected data into theme codes using deductive coding. The theme codes were based on the literature review (i.e. administrative data, clinical data, medication data and related subthemes). Next, the coding scheme was optimized through discussion between both interviewers and applied to all interviews. Data coding and analysis was executed using Nvivo 11 qualitative data analysis software. In the interpretation phase, in line with the thematic analysis, commonalities and differences were identified, relationships between different themes were explored and descriptive and/or explanatory conclusions were made for each theme. ${ }^{16}$ Finally, the findings were discussed and interpreted within the multidisciplinary research team (JW, MVDG, VF, JDL) and led to the finalization of the prototype of a discharge report. In this decision making process, we considered the arguments and examples of healthcare professionals on what information should (not) be exchanged and why. Secondary to that, we took into account how often arguments recurred to estimate the possible support for these particular concerns.

\subsubsection{Ethics approval}

The protocol of the semi-structured interviews was approved by the Ethics Committee of UZ/KU Leuven (s58480). Written informed consent was obtained from all individual participants included in the study.

\section{Results}

Literature review and construction of a preliminary discharge report

In total, 26 initiatives from nine different countries were selected
(Table 1). ${ }^{6,7}, 19-47$ A flowchart of the literature selection is displayed in Supplementary material 2 . The majority of the initiatives were re-

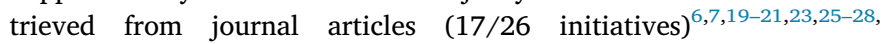
$30,32,33,35-37,39,41,43,45-47$; six from guidelines ${ }^{29,34,38,40,42,44}$ and three local initiatives ${ }^{22,24,31}$ were included in the review.

The content of the exchanged information upon hospital discharge from the different initiatives were compared and presented in Supplementary material 3 . Of the 26 initiatives, 12 contained an example of the discharge document. ${ }^{7,22-27,29,31,33,34,40}$ In total, 49 different items were documented and categorized into three categories (administrative, medical and medication data). Aside from this variability in exchanged information, there was a lack of detailed description of the content and lack of argumentation why information was or was not exchanged. Likewise, the author of the information and the communication channel were not consistently reported in literature. None of the initiatives researched the accuracy of the content that was being exchanged. Therefore, the quality of the exchanged information could not be guaranteed and the implementation of the study procedures was questionable.

Overall, recurring administrative data included the patient's name, date of birth, sex, period of hospitalization, hospital contact information (i.e. name of the treating hospital physician, hospital department, phone number and e-mail address) date and author of the discharge report. Recurring medical data includes reason(s) for hospitalization, comorbidities, weight and height, (drug) allergies, blood pressure and lab values including renal function. Finally, recurring medication data consisted of drug indications, a start and stop date, a list of the medication at hospital admission as well as a list at discharge. Moreover, the reasons for drug therapy changes were also frequently shared. Based on these findings, a preliminary discharge report was constructed.

\subsection{Validation of the discharge report}

\subsubsection{Participant characteristics}

Nineteen interviews were carried out in 2 regions in Belgium, Leuven $(\mathrm{CP}=5 ; \mathrm{GP}=7)$ and Bruges $(\mathrm{CP}=5 ; \mathrm{GP}=2)$, between November 2015 and April 2016. Table 2 provides an overview of the participant's characteristics. The duration of the entire interviews ranged from 37 to $90 \mathrm{~min}$. One general practitioner refused to have the interview audiotaped. For this interview, field notes were taken.

\subsubsection{Content of the discharge report}

Table 3 shows the items that were present in the preliminary discharge report and the main results of the interviews. Illustrative quotes are shown in Table 4. No objections were made for including the patient's name, sex, general practitioner and period of hospitalization in the discharge report. Pharmacists argued that the period of hospitalization would be beneficial to indicate the severity of the hospitalization. The dates could also be taken into account for medication compliance and illustrate how long ago the patient was discharged. Additionally, it was suggested to add the contact information of the GP, to register the patient's regular pharmacy and the identification number of the patient for insurance purposes.

Secondly, pharmacists expressed great interest to receive contact information of the hospital (i.e. name of the treating hospital physician, hospital department, phone number). Currently, contacting the hospital physician is a time-consuming and discouraging process. In spite of some HCPs being very enthusiastic about this information, two GPs emphasized that the GP should coordinate patient's care and therefore be the primary contact person for community pharmacists.

Third, medical data were discussed in the interviews. Overall, the majority of HCPs could see the value of sharing the reason for hospitalization and comorbidities with the community pharmacist. However, one GP stated that reasons for hospitalizations should only be shared if relevant for the $\mathrm{CP}$, for instance if the hospitalization was related to drug use. Both GPs and CPs argued that information on medical history 


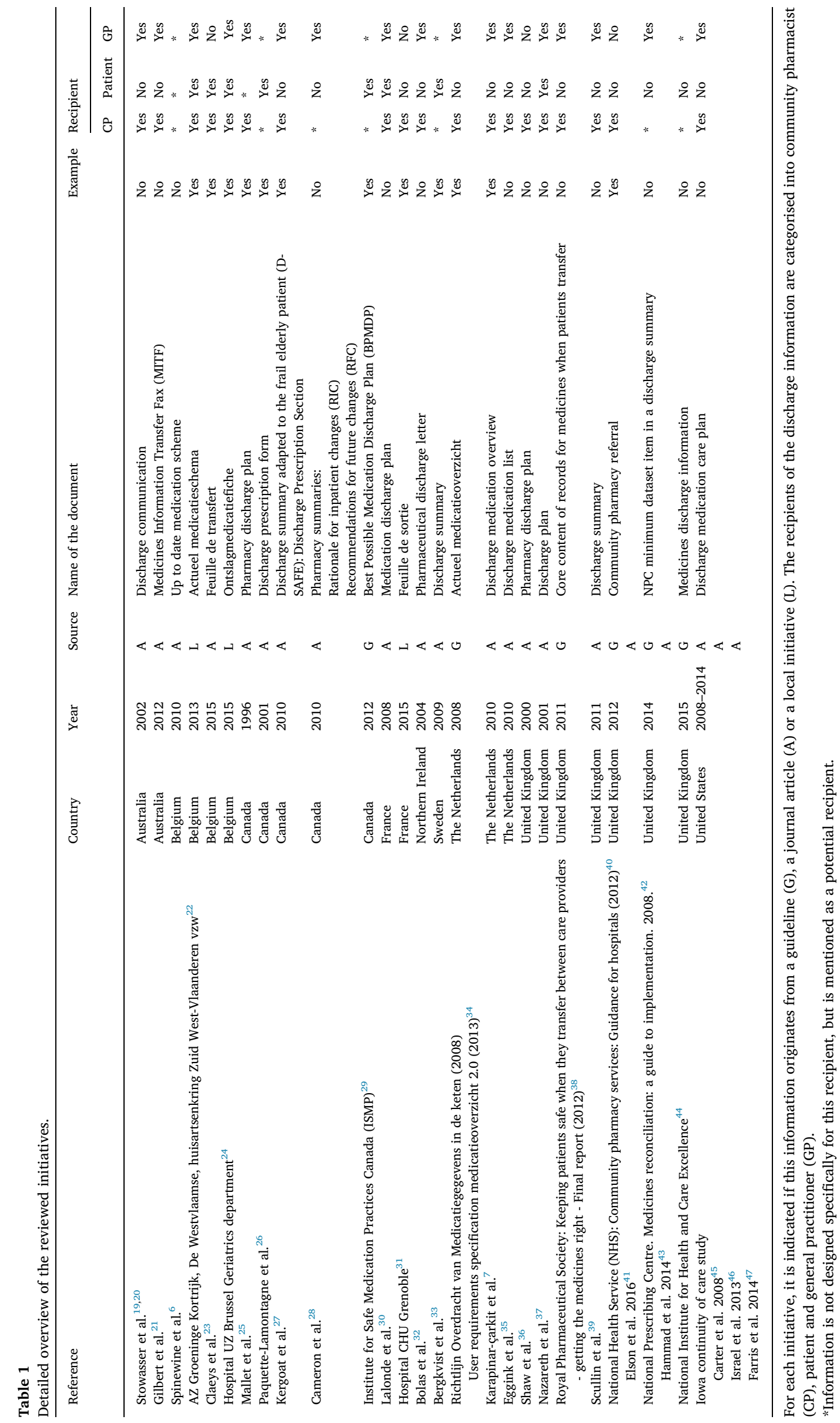


Table 2

Characteristics of the participants.

\begin{tabular}{|c|c|c|c|}
\hline Characteristic & $\begin{array}{l}\text { General } \\
\text { practitioners }\end{array}$ & $\begin{array}{l}\text { Community } \\
\text { pharmacists }\end{array}$ & Total \\
\hline $\mathrm{N}$ & 9 & 10 & 19 \\
\hline \multicolumn{4}{|l|}{ Region } \\
\hline - Leuven & 7 & 5 & $12 / 19$ \\
\hline - Bruges & 2 & 5 & $7 / 19$ \\
\hline Gender (female) & 5 & 6 & $11 / 19$ \\
\hline \multicolumn{4}{|l|}{ Clinical experience } \\
\hline$-<10$ years & 3 & 0 & $3 / 19$ \\
\hline - 10-20 years & 2 & 5 & $7 / 19$ \\
\hline$->20$ years & 4 & 5 & $9 / 19$ \\
\hline Opinion leaders (yes) & 5 & 6 & $9 / 19$ \\
\hline
\end{tabular}

Table 3

Items in a discharge report based on 19 interviews.

\begin{tabular}{lll}
\hline Item & Relevance $^{\mathrm{a}}$ & $\begin{array}{l}\text { Final discharge } \\
\text { report }\end{array}$ \\
\hline Administrative data & & \\
- Name, sex & ++ & Yes \\
- Period of hospitalization & ++ & Yes \\
- GP name & ++ & Yes \\
- Hospital contact information & + & Yes \\
Medical data & & \\
- Reason for hospitalization & + & Yes \\
- Comorbidities & + & Yes \\
- Weight and height & + & No \\
- Allergies & ++ & Yes \\
- Blood pressure & \pm & No* \\
- Lab values (K ${ }^{+},{ }^{+}$Na ${ }^{*}$ INR, Digoxin) & - & No \\
- Renal function & ++ & No* \\
Medication data & & \\
- Admission list & ++ & Yes \\
- Reason for starting, adjusting or stopping & + & Yes \\
a drug & & \\
- Drug indication & + & Yes \\
- Active compound & - & No \\
- Start and stop date per drug & ++ & Yes \\
\hline
\end{tabular}

The listed items were present in the preliminary discharge report, based on their relevance as discussed in the interviews, part of the items were retained in the final discharge report.

++ All respondents agreed this information should be shared with the CP after discharge.

+ The majority of respondents indicated the information should be shared.

\pm No consensus among respondents.

- The majority of respondents indicated the information should not be shared. - All respondents agreed this information should not be shared with the CP after discharge or that the exchange would have no added value.

* The clinical or lab values as such are not included in the final version of the discharge report but a diagnosis of hypertension or chronic kidney disease is registered in the discharge report under comorbidities.

a The relevance of each item was categorised into five levels (ranging from to ++$)$.

and comorbidities could potentially be useful to help interpret the medication list and could be a valuable source of validated and trustworthy information. One GP demonstrated the added value for patient safety if a pharmacist is aware of a history of stomach ulcers and takes this information into account when dispensing over the counter drugs. However, another GP expressed concerns for sharing information such as psychiatric comorbidities and questioned the relevance of this information for a CP. The utility of the height and weight of the patient on the discharge report was disputed. In contrast, all respondents agreed (drug) allergy information should be transferred across settings to ensure patient safety.
In a next step, the exchange of blood pressure, renal function and other lab values such as potassium, sodium, INR and digoxin concentrations were discussed. Blood pressure values were not considered as relevant. Arguments included the variability of the measure over time, the patient and situation specific nature of the value, and the importance of correct interpretation. Respondents (both GPs and CPs) rather suggested including the diagnosis of hypertension in the comorbidity list. Comparable arguments were made for the exchange of lab values. In these discussions with CPs and GPs, the importance of upto-date information was also emphasized. One pharmacist questioned how it would be decided which values are displayed and which not. He suggested only showing values that are not within the normal range. In the proposal, aside from the actual result of the lab test, the date of test and the normal range of the lab value were shown as well. Nonetheless, concerns were expressed on what would happen if a pharmacist would not have the most recent lab values. Moreover, both GPs and CPs agreed that education on interpreting the lab values is required for high-quality patient care. Pharmacists acknowledged they have not received sufficient education on this matter. Upon education, the majority of CPs found lab values valuable information. It was argued on the one hand that this information could allow the pharmacist to perform an additional check before drugs are dispensed and therefore enhance patient safety. On the other hand, reservation existed also among GPs and CPs as to what responsibilities this information would bring and how it would affect the role of the CP. Both HCPs agreed the general practitioner is the primary HCP to manage a patient's health and request, interpret and follow up lab values.

The significance of renal function for the use of medication was acknowledged by both groups of HCPs. Both for over-the-counter and prescribed medication, the pharmacist could perform an additional verification to make sure the drug and dosage is adapted to the renal function. Nevertheless, the reservations for sharing blood pressure and other lab values are also valid arguments in the discussion on the exchange of renal function. One GP gave the example that one lab value does not allow a differentiation between a diagnosis of acute and chronic kidney disease. Therefore, multiple respondents postulated sharing chronic kidney disease and the stage of the disease as a diagnosis rather than the renal function itself.

In contrast to a basic medication list containing the medication regimen at hospital discharge, the discharge report contained additional medication data. For one, the discharge report displayed the medication list of a patient as registered at hospital admission. The value of this information was acknowledged unanimously. The respondents indicated this information would be beneficial to verify that all drugs were registered upon hospital admission, to follow up changes in drug regimen, to confirm and reconcile with prescriptions and to counsel patients.

Secondly, reasons for starting, adjusting or stopping the drug regimen were incorporated in the proposal. All but one GP found this information valuable. Pharmacists stated they are confronted with patients questioning the reasons for adjustments in drug regimen and have to guess why adjustments were made. Moreover, pharmacists noticed this lack of information hinders patient counselling, undermines patient involvement and results in patients who are not motivated and are not convinced about the drug therapy. Therefore, this verified information is of great value for patient counselling and can reinforce the treatment as intended by the treating physicians. Barriers included the timeconsuming nature of registering this information in the hospital. One GP feared that if multiple HCPs informed patients on drug alterations, it could result in mixed messages and confused patients.

Third, the indication of each drug was added to the medication list. Although some CPs stated that this information was already known for regular patients and straightforward for some drugs, the majority of CPs and GPs perceived it as useful. Knowing drug indications would allow pharmacists to tailor advice to the specific indication or situation of the patient. Moreover, the indication of a drug could determine whether a 
Table 4

Illustrative quotes about the relevance of the items in the discharge report.

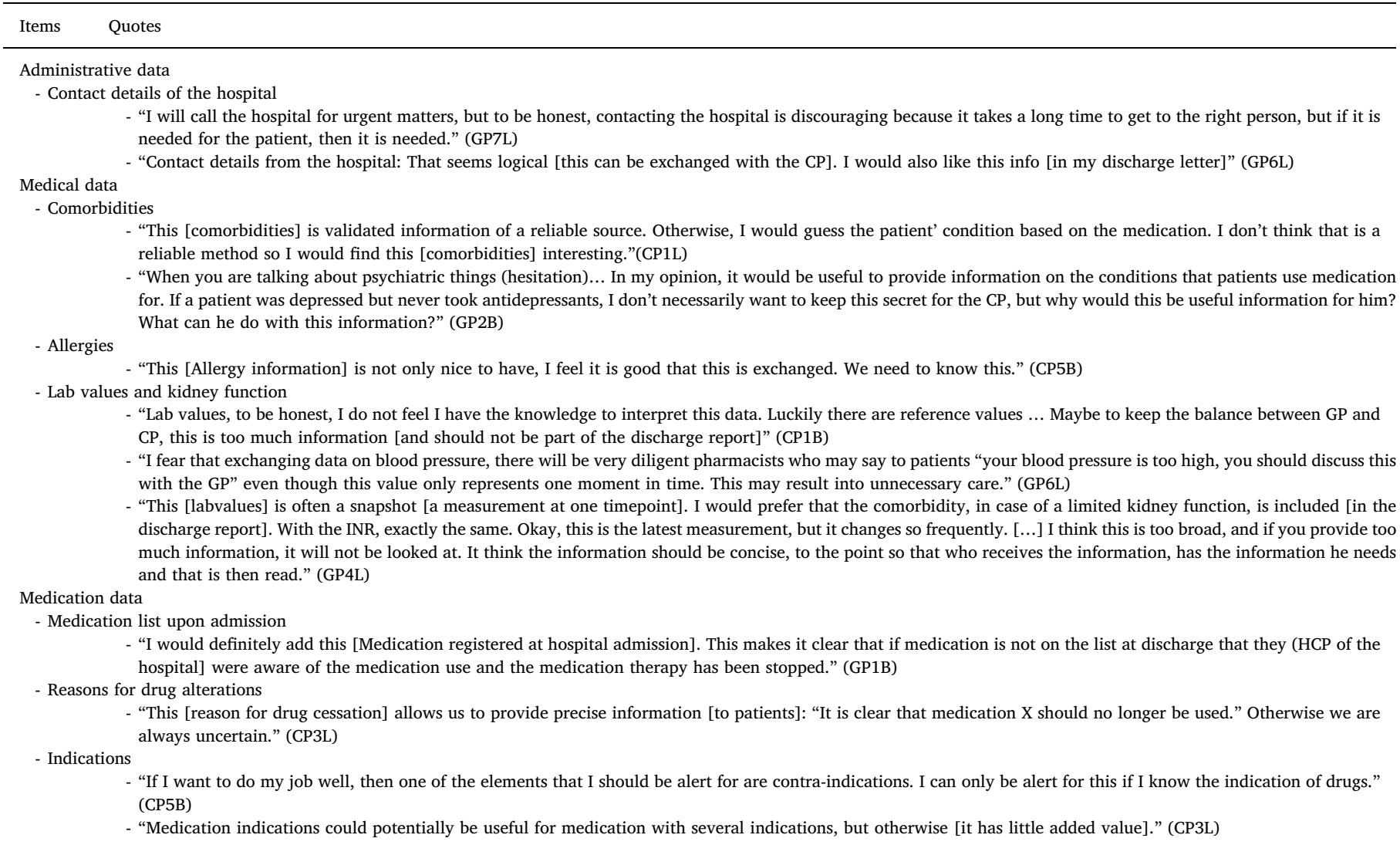

A code was given to each participant containing a character based on their profession (general practitioner or community pharmacist), a chronological number based on the date of the interview and a character based on the care region (Bruges or Leuven).

patient is eligible for additional drug reimbursement. ${ }^{1}$ For this purpose, it was also suggested to add information on the reimbursement status of drugs (requested, granted or denied). Finally, some respondents remarked that comorbidities and indications contain overlapping information, and they perceived that the added value of indication was limited. One GP argued that a history of a stomach ulcer is a relevant comorbidity in a discharge document, even if there is no current treatment required.

Finally, adding the active compound to the medication list was considered unnecessary in a discharge report for the community pharmacist. The stop date of medication was considered useful, especially for acute drugs. Other suggestions included adding the last date and time that the drug was administered in the hospital. This would be valuable for drugs that should not be administered on a daily basis or have a narrow therapeutic range.

Based on these findings from the interviews, the discharge report was optimized (Table 3). Both the indication and comorbidities were incorporated in the document. In line with the feedback of interviewees, the renal function was not included in the final discharge report but chronic or acute kidney disease (including the stage of the disease) would be registered in the comorbidity list. The final, validated prototype of a discharge report can be found in Fig. 1.

\footnotetext{
${ }^{1}$ In Belgium, some drugs require an additional document for drug reimbursement. To qualify for this reimbursement, the treating physician should fill out a request with patient information and indicate the patient meets the requirements for additional reimbursement. If the attestation is granted, the community pharmacist can dispense the drug at a reduced rate.
}

\section{Discussion}

\subsection{Main findings}

This research generated an evidence-based prototype of a discharge report for the community pharmacist. The report was constructed and validated using two methods: a literature review to identify information that is exchanged with the $\mathrm{CP}$ at discharge and semi-structured interviews with HCPs in primary care to assess the relevance of the content. The final discharge report contains concise medical data (including reasons for hospitalization, comorbidities and allergies), medication data and administrative data (e.g. hospital contact information). The medication data encompasses a medication list at hospital admission and discharge, reasons for drug adjustments, drug indications and start/ stop dates.

The content of this prototype is tailored to the informational needs of community pharmacists. Although their needs have been documented in several countries, the literature review found only six guidelines for information exchange with the $\mathrm{CP}$ originating from three countries. ${ }^{29,34,38,40,42,44}$ The developed discharge report strongly contrasts to a basic medication list which can be shared with the $\mathrm{CP}$ through the Vitalink platform in Belgium. This research has shown that a basic medication list does not fully meet the pharmacist's information needs after hospital discharge. This research established that additional medical, medication and administrative data is preferred.

In contrast to expectations, HCPs in Belgium were hesitant to exchange data on renal function and other lab values in spite of acknowledging the importance of renal function for drug therapy. The interviews uncovered that there is a risk of misinterpretation of the data, and exchange of data is accompanied with a responsibility to act 


\section{Discharge report (part A)}

\begin{tabular}{ll}
\hline \multicolumn{2}{|l}{ Administrative data } \\
\end{tabular}

\section{Medical data}

\section{Clinical data}

Reason of

hospitalization

Comorbidities

Allergies

- Allergen

- Reaction

- Date
Heart failure

- Bilateral cataract (operation in 2010)

- Arterial hypertension

- Heart failure (NYHA III)

- Chronic kidney disease stage 2 (GFR: $65 \mathrm{~mL} / \mathrm{min} / 1.73 \mathrm{~m}^{2}$ )

Clindamycine

Skin reaction 19/05/15

\section{Discharge report (part B)}

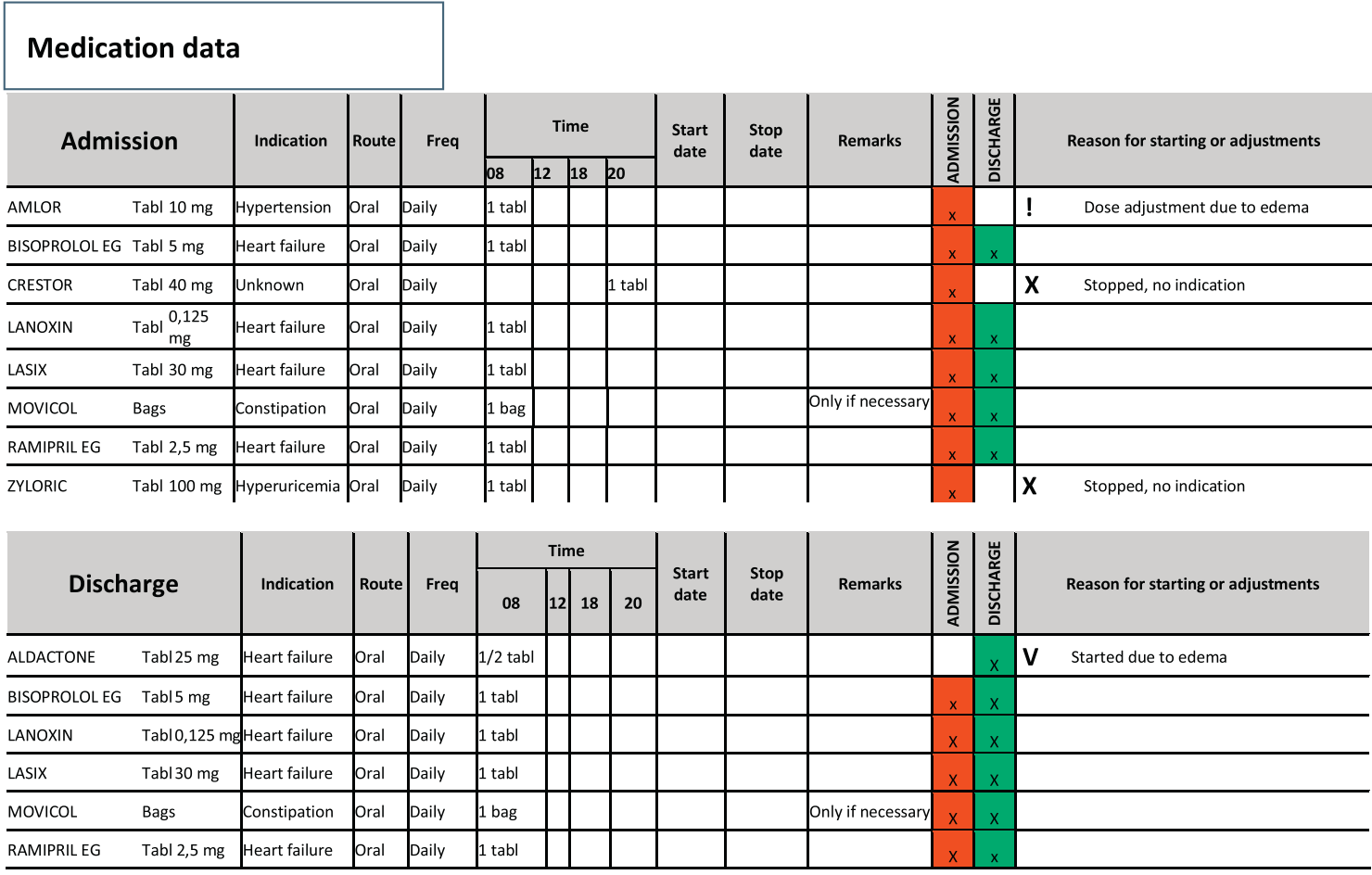

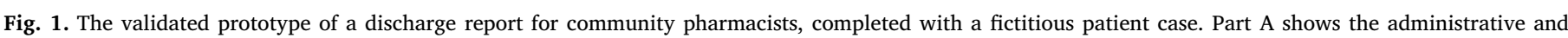
medical data. Part B displays the medication data.

on the information. Pharmacists indicated they require additional education on this matter before this information should be exchanged. In the Belgian context, it is not standard practice to exchange clinical information with the community pharmacist. Contrastingly, the literature review found five initiatives where renal function was exchanged with the CP. ${ }^{7,25,27,31,34}$ Given that the education level of pharmacists with regard to lab values may differ across countries, the decision not to exchange lab values may not be transferrable to other countries and settings. For the Belgian setting, it is recommended to revisit this decision at a later timepoint given the evolutions in education and increase in pharmaceutical care services.

Six articles explored experiences and expectations of pharmacists related to discharge information via interviews and/or questionnaires. ${ }^{19,23,32,48-50}$ These articles confirmed the necessity of sharing 
the medication-related data. A questionnaire in the United Kingdom in 1997 already revealed that the majority of CPs $(94 \% ; n=33)$ and GPs ( $96 \% ; n=71)$ desire to receive reasons for drug therapy changes after hospitalization. ${ }^{49}$ In 2011, a Belgian questionnaire explored which information CPs find indispensable using a 26-item questionnaire $(\mathrm{n}=309) .{ }^{23}$ A majority of participants considered reasons for hospitalization, reasons for drug alterations and drug indication indispensable or useful information. However, for confidentiality reasons these elements were not retained in a subsequent intervention study. ${ }^{23}$ This demonstrates the sensitivity of exchanging patient information between healthcare providers.

\subsection{Evidence}

Information exchange is a promising strategy to ensure continuity of care and patient safety. ${ }^{32}$ A discharge report for the community pharmacy can facilitate medication reconciliation after hospital discharge and allow customization of counselling to the patient's specific situation. Participants of this study gave examples how certain information could contribute to patient safety. However, current evidence is limited. Grey et al. found a discharge letter for the community pharmacist to have a positive effect on the implementation of treatment plans. ${ }^{51}$ Hockly et al. demonstrated that sharing the GP's discharge letter with the $\mathrm{CP}$ reduced the number of post-discharge prescribing discrepancies and reduced discrepancies between the patients' self-described medication regimen and the discharge letter. ${ }^{52}$ However, sharing a discharge medication plan with the physician and pharmacist did not reduce the number of adverse events and readmission rate in the study of Farris et al. ${ }^{47}$ These studies were not incorporated in this review because no detailed information was provided about the content of the discharge report. To the best of our knowledge, there are no impact studies with discharge reports for the CP that provide: (1) a description of and (2) argumentation for the content, (3) the author of the document, (4) the communication channel and (5) assess the quality of the document. Further research, with adequate reporting of these elements, is needed to confirm the added value of this discharge report on continuity of care and patient safety.

\subsection{Limitations and strengths}

It is a strength that this research combined a literature review and semi-structured interviews for the development of the discharge report (method triangulation). To our knowledge, this is the first article to provide an overview of national and international initiatives of information exchange with the CP. Only one database was consulted by one researcher, but this probably did not significantly impact the findings. The purpose of the review was to summarize the exchanged information in the identified initiatives. Many items for a discharge report recurred in several initiatives. In the decision-making process, a multidisciplinary team discussed the findings and constructed the preliminary discharge report.

It is a strength that the subsequent semi-structured interviews actively involved both community pharmacists and general practitioners (data triangulation). The sampling strategy included both opinion and non-opinion leaders from two regions in Belgium which lead to maximal variation in the participants (data triangulation). This strengthens the generalizability of the findings. In addition, participants were given the opportunity to add elements to the discharge report. This further supports the statement that the main elements for a discharge report were covered in this research. However, it is a limitation that the patients' perspective related to information exchange and the perspective of HCPs in the hospital, who could reflect on the feasibility and implementation of a discharge report in practice, were not incorporated in this research. This should be addressed in future research.

The researchers purposefully did not choose a traditional consensusbased approach such as a Delphi method. In the opinion of the research team, a consensus-based method cannot provide as much insights into the different arguments of HCPs, and to disclose advantages and potential pitfalls of information exchange. In contrast to a previous questionnaire on the subject, ${ }^{23}$ these semi-structured interviews provided insights into the aspects that the respondents perceived as important or had a strong opinion about. As a result, not all elements of the discharge report were discussed in as much detail in every interview. The participants were asked to illustrate their statements with examples from practice which strengthens the credibility of the findings. A focus group design would have allowed direct interaction between different participants but may have discouraged HCPs to voice their opinion. Overall, during the review and validation of the discharge report by healthcare professionals, patient safety, as well as patient privacy, roles and responsibilities of HCPs were taken into consideration.

\subsection{Implementation of the discharge report in practice}

This research identified relevant information to exchange with the community pharmacist at hospital discharge. In the study by Claeys et al. certain information was not exchanged with the CP due to privacy reasons. ${ }^{23}$ Likewise, concerns regarding a patient's privacy were expressed during the interviews. The recent European General Data Protection Regulation (GDPR) provides a regulatory framework. GDPR states that in general, it is prohibited to process (and this includes the exchange of) health data. However, an exception is made if the exchange is necessary for the provision of healthcare and it involves professionals who have a professional secrecy or if the patient has provided explicit informed consent for the exchange of data (Art 9 GDPR). ${ }^{53}$

Moreover, the added value of this discharge report will depend on multiple factors. A first factor to consider is the quality of the data. Research has demonstrated discrepancies between the documentation for the patient, $\mathrm{CP}$ and the GP. ${ }^{21,54} \mathrm{~A}$ transcription burden is known to increase the risk of errors. ${ }^{55}$ The time-consuming nature of writing a discharge report was also noted in the interviews as a barrier for implementation. Therefore, the researchers advocate for an automatic software generation of a discharge report, based on the electronic patient records in the hospitals. Secondly, the availability, accessibility and safe exchange of the discharge information is crucial. Upon receiving information, a third factor is the responsible use of the information.

\section{Conclusion}

The literature review and semi-structured interviews with Belgian healthcare professionals in primary care, resulted in an evidence-based prototype of a discharge report for the community pharmacist. This discharge report contains concise medical data (including reasons for hospitalization, comorbidities and allergies), medication data and administrative data (e.g. hospital contact information). The exchange of this type of information with the community pharmacist might contribute to patient safety after hospital discharge and continuity of care.

\section{Clinical trial registration information}

Retrospectively registered in clinicaltrials.gov (number NCT03223584).

\section{Funding}

This research did not receive any specific grant from funding agencies in the public, commercial, or not-for-profit sectors. 


\section{Declarations of interest}

None.

\section{Acknowledgments}

The authors thank the community pharmacists and general practitioners who participated in the interviews for their critical review of the preliminary discharge report.

\section{Appendix A. Supplementary data}

Supplementary data to this article can be found online at https:// doi.org/10.1016/j.sapharm.2019.04.049.

\section{References}

1. International Organization for Standardization. Health Informatics - System of Concepts to Support Continuity of Care. 2015; 2015 Accessed February 1, 2018 www. iso.org/iso/catalogue_detail.htm? csnumber $=58102$.

2. Paulino EI, Bouvy ML, Gastelurrutia MA, Guerreiro M, Buurma H. Drug related problems identified by European community pharmacists in patients discharged from hospital. Pharm World Sci. 2004;26(6):353-360.

3. Forster AJ, Clark HD, Menard A, et al. Adverse events among medical patients after discharge from hospital. CMAJ (Can Med Assoc J). 2004;170(3):345-349.

4. García-Pérez L, Linertová R, Lorenzo-Riera A, Vázquez-Díaz JR, Duque-González B, Sarría-Santamera A. Risk factors for hospital readmissions in elderly patients: a systematic review. QJM. 2011;104(May):639-651. https://doi.org/10.1093/qjmed/ hcr070.

5. Leendertse AJ, Egberts ACG, Stoker LJ, van den Bemt PMLA. Frequency of and risk factors for preventable medication-related hospital admissions in The Netherlands. Arch Intern Med. 2008;168(17):1890-1896.

6. Spinewine A, Foulon V, Claeys C, et al. Continuïteit van de medicamenteuze behandeling tussen ziekenhuis en thuis. Health Services Research (HSR). Brussel: Federaal Kenniscentrum voor de Gezondheidszorg (KCE). KCE Reports 131A. 2010; 2010.

7. Karapinar-Çarkıt F, Borgsteede SD, Zoer J, et al. The effect of the COACH program (Continuity of Appropriate pharmacotherapy , patient Counselling and information transfer in Healthcare) on readmission rates in a multicultural population of internal medicine patients. BMC Health Serv Res. 2010;10:39. https://doi.org/10.1186/14726963-10-39.

8. Kripalani S, LeFevre F, Phillips CO, Williams MV, Basaviah P, Baker DW. Deficits in communication and information transfer between hospital-based and primary care physicians. J Am Med Assoc. 2007;297(8):831-841. https://doi.org/10.1001/jama. 297.8.831.

9. Ooi CE, Rofe O, Vienet M, Elliott RA. Improving communication of medication changes using a pharmacist-prepared discharge medication management summary Int J Clin Pharm. 2017;39(2):394-402. https://doi.org/10.1007/s11096-017-0435-5.

10. Karapinar F, van den Bemt PML a, Zoer J, Nijpels G, Borgsteede SD. Informational needs of general practitioners regarding discharge medication: content, timing and pharmacotherapeutic advice. Pharm World Sci. 2010;32(2):172-178. https://doi. org/10.1007/s11096-009-9363-3.

11. Nazar H, Nazar Z, Portlock J, Todd A, Slight SP. A systematic review of the role of community pharmacies in improving the transition from secondary to primary care. Br J Clin Pharmacol. 2015;80(5):936-948. https://doi.org/10.1111/bcp.12718.

12. Rijksinstituut voor ziekte- en invaliditeitsverzekering. Een nieuwe dienst van de apotheker voor chronische astmapatiënten: het begeleidingsgesprek voor goed gebruik van geneesmiddelen (GGG). 18/05/2017. 2017; 2017 Accessed March 16, 2019 https:// www.riziv.fgov.be/nl/professionals/individuelezorgverleners/apothekers/Paginas/ begeleiding-apotheker-astmapatient-info-apotheker.aspx.

13. Rijksinstituut voor ziekte- en invaliditeitsverzekering (RIZIV/INAMI/NIHDI). Vanaf $1 \mathrm{mei}$ 2018: opvolging van een patiënt met diabetes type 2/voortraject - educatie over therapietrouw. 2018; 2018 Accessed April 10, 2019 https://www.riziv.fgov.be/nl professionals/individuelezorgverleners/apothekers/Paginas/diabetes-type2voortraject-educatie-therapietrouw.aspx.

14. Rijksinstituut voor ziekte- en invaliditeitsverzekering (RIZIV). Begeleiden van chronische patiënten als huisapotheker. 9/11/2017. 2017; 2017 Accessed December 15, 2017 http://www.riziv.fgov.be/nl/professionals/individuelezorgverleners/apothekers/ Paginas/huisapotheker-begeleiden-chronische-patienten.aspx.

15. Storms H, Marquet K, Nelissen K, Hulshagen L, Lenie J, Remmen R. Implementing an electronic medication overview in Belgium. BMC Res Notes. 2014;7(1):915.

16. Gale NK, Heath G, Cameron E, Rashid S, Redwood S. Using the framework method for the analysis of qualitative data in multi-disciplinary health research. BMC Med Res Methodol. 2013;13(1):117. https://doi.org/10.1186/1471-2288-13-117.

17. Foulon V, Wuyts J, Desplenter F, et al. Problems in continuity of medication management upon transition between primary and secondary care: patients' and professionals' experiences. Acta Clin Belg. 2018(22):1-9. https://doi.org/10.1080/ 17843286.2018.1483561 June.

18. Moser A, Korstjens I. Series: practical guidance to qualitative research. Part 3: sampling, data collection and analysis. Eur J Gen Pract. 2018;24(1):9-18. https://doi. org/10.1080/13814788.2017.1375091.
19. Stowasser DA, Collins DM, Stowasser M. A randomised controlled trial of medication liaison services - acceptance and use by health professionals. $J$ Pharm Pract Res. 2002;32(3):221-226. https://doi.org/10.1002/jppr2002323221.

20. Stowasser DA, Collins DM, Stowasser M. A randomised controlled trial of medication liaison services - patient Outcomes. J Pharm Pract Res. 2002;32(3):221-226. https:// doi.org/10.1002/jppr2002323221.

21. Gilbert AV, Patel B, Morrow M, Williams D, Roberts MS, Gilbert AL. Providing community-based health practitioners with timely and accurate discharge medicines information. BMC Health Serv Res. 2012;12(1):453. https://doi.org/10.1186/14726963-12-453.

22. Hospital AZ Groeninge - Kortrijk - Belgium, Westvlaamse D, Vzw Huisartsenkring ZW-V. Actueel Medicatieschema. 2013; 2013https://www.azgroeninge.be/EN/start/PDF/ thuismedicatie.pdf

23. Claeys C, Dufrasne M, C DV, et al. Transmission d'information au pharmacien d'officine après hospitalisation du patient: élaboration d'une feuille de transfert, évaluation prospective de son effet, et enquête sur les besoins d'information des pharmaciens. J Pharm Belg. 2015;1:42-54.

24. University Hospital Brussels (UZ Brussel). Ontslagmedicatiefiche. 2015; 2015.

25. Mallet L, Laprise R, Bergeron J. Pharmacy discharge plan for continuity in patient care. Can Pharm J. 1996:131(1):21-23.

26. Paquette-lamontagne N, Mclean WM, Besse L, Cusson J. Evaluation of a new in tegrated discharge prescription form. Ann Pharmacother. 2001;35(7-8):953-958.

27. Kergoat M-J, Latour J, Julien I, et al. A discharge summary adapted to the frail elderly to ensure transfer of relevant information from the hospital to community settings: a model. BMC Geriatr. 2010;10:69. https://doi.org/10.1186/1471-231810-69.

28. Cameron B. The impact of pharmacy discharge planning on continuity of care. Can $J$ Hosp Pharm. 1994;47(3):101-109.

29. ISMP Canada. Best Possible Medication Discharge Plan (BPMDP). 2012; 2012

30. Lalonde L, Lampron AM, Vanier MC, Levasseur P, Khaddag R, Chaar N. Effectiveness of a medication discharge plan for transitions of care from hospital to outpatient settings. Am J Heal Pharm. 2008;65:1451-1457. https://doi.org/10.2146/ ajhp070565.

31. Hospital CHU Grenoble. Feuille de Sortie.; 2015.

32. Bolas H, Brookes K, Scott M, Mcelnay J. Evaluation of a hospital-based community liaison pharmacy service in Northern Ireland. Pharm World Sci. 2004;26(2):114-120. https://doi.org/10.1023/B:PHAR.0000018601.11248.89.

33. Bergkvist A, Midlöv P, Höglund P, Larsson L, Bondesson A, Eriksson T. Improved quality in the hospital discharge summary reduces medication errors-LIMM: landskrona Integrated Medicines Management. Eur J Clin Pharmacol. 2009;65(10):1037-1046. https://doi.org/10.1007/s00228-009-0680-1.

34. Actiz FNT, GGZ, et al. Richtlijn Overdracht van Medicatiegegevens in de keten [Guideline transmission of medication data between settings]. 2008; 2008 Accessed February 1, 2018 https://www.knmg.nl/advies-richtlijnen/knmg-publicaties/overdracht-vanmedicatiegegevens-in-de-keten.htm.

35. Eggink RN, Lenderink AW, Widdershoven JWMG, van den Bemt PMLA. The effect of a clinical pharmacist discharge service on medication discrepancies in patients with heart failure. Pharm World Sci. 2010;32(6):759-766. https://doi.org/10.1007/ s11096-010-9433-6.

36. Shaw H, Mackie CA, Sharkie I. Evaluation of effect of pharmacy discharge planning on medication problems experienced by discharged acute admission mental health patients. Int J Pharm Pract. 2000;8(2):144-153. https://doi.org/10.1111/j.20427174.2000.tb00999.x.

37. Nazareth I, Burton A, Shulman S, Smith P, Haines A, Timberall H. A pharmacy discharge plan for hospitalized elderly patients-a randomized controlled trial. Age Ageing. 2001;30:33-40

38. Royal Pharmaceutical Society. Keeping Patients Safe when They Transfer between Care Providers - Getting the Medicines Right: Good Practice Guidance for Healthcare Professions. 2011; 2011

39. Scullin C, Hogg A, Luo R, Scott MG, McElnay JC. Integrated medicines management can routine implementation improve quality? J Eval Clin Pract. 2012;18(4):807-815. https://doi.org/10.1111/j.1365-2753.2011.01682.x.

40. National Health Service, Royal Pharmaceutical Society, PSNC, NHS Employers, PSNC. Guideline: Community Pharmacy Services Guidance for Hospitals. 2012; 2012http:// www.nhsemployers.org/case-studies-and-resources/2012/01/communitypharmacy-services-guidance-for-hospitals.

41. Elson R, Cook H, Blenkinsopp A. Patients' knowledge of their new medicines after discharge from hospital: what are the effects of nurse, doctor or pharmacist counselling and medicines use reviews (MURs)? Res Soc Adm Pharm. 2017;13(3):628-633https://doi.org/10.1111/ijpp.12146.

42. National Prescribing Centre, National Health Service. Medicines Reconciliation: A Guide to Implementation. doi:10.1353/fih.0.0063.

43. Hammad EA, Wright DJ, Walton C, Nunney I, Bhattacharya D. Adherence to UK national guidance for discharge information: an audit in primary care. Br J Clin Pharmacol. 2014;78(6):1453-1464. https://doi.org/10.1111/bcp.12463.

44. National Institute for Health and Care Excellence (NICE). Medicines Optimisation: The Safe and Effective Use of Medicines to Enable the Best Possible Outcomes. 2015; 2015.

45. Carter BL, Farris KB, Abramowitz PW, et al. The Iowa continuity of care study: background and methods. Am J Health Syst Pharm. 2008;65(17):1631-1642. https:// doi.org/10.2146/ajhp070600 (The).

46. Israel EN, Farley TM, Farris KB, Carter BL. Underutilization of cardiovascular medications: effect of a continuity-of-care program. Am J Health Syst Pharm. 2013;70(18):1592-1600. https://doi.org/10.1097/MPG.0b013e3181a15ae8 Screening).

47. Farris KB, Carter BL, Xu Y, et al. Effect of a care transition intervention by pharmacists: an RCT. BMC Health Serv Res. 2014;14(1):406. https://doi.org/10.1186/ 
1472-6963-14-406.

48. Kennelty K, Chewning B, Wise M, Kind A, Roberts T, Kreling D. Barriers and facilitators of medication reconciliation processes for recently discharged patients from community pharmacists' perspectives. Res Soc Adm Pharm. 2015;11(4):517-530. https://doi.org/10.1016/j.sapharm.2014.10.008.

49. Munday A, Kelly B, Forrester JWE, Timoney A, MCGovern E. Do general practitioners and community pharmacists want information on the reasons for drug therapy changes implemented by secondary care? BJGP. 1997;47:563-566.

50. Urban R, Paloumpi E, Rana N, Morgan J. Communicating medication changes to community pharmacy post-discharge: the good, the bad, and the improvements. Int $J$ Clin Pharm. 2013;35(5):813-820. https://doi.org/10.1007/s11096-013-9813-9.

51. Gray S, Urwin M, Woolfrey S, Harrington B, Cox J. Copying hospital discharge summaries to practice pharmacists: does this help implement treatment plans? Qual Prim Care. 2008;16(5):327-334.
52. Hockly M, Williams S, Allen M. Transfer of care - a randomised control trial investigating the effect of sending the details of patients' discharge medication to their community pharmacist on discharge from hospital. Int $J$ Pharm Pract 2018;26(2):174-182. https://doi.org/10.1111/ijpp.12364.

53. Regulation ( EU. The European Parliament and of the Council of 27 April 2016 on the Protection of Natural Persons with Regard to the Processing of Personal Data and on the Free Movement of Such Data, and Repealing Directive 95/46/EC (General Da. 2016/679 of; 2016/679 of.

54. Cornu P, Steurbaut S, Leysen T, et al. Discrepancies in medication information for the primary care physician and the geriatric patient at discharge. Ann Pharmacother. 2012;46(7-8):983-990. https://doi.org/10.1345/aph.1R022.

55. Dean B, Schachter M, Vincent C, Barber N. Causes of prescribing errors in hospital inpatients: a prospective study. Lancet. 2002;359(9315):1373-1378. https://doi.org/ 10.1016/S0140-6736(02)08350-2. 